\title{
0.125\% Bupivacaine Versus 0.2\% Ropivacaine for Labour Epidural Analgesia: A Comparative Study
}

\author{
Dr. Deepali Valecha ${ }^{1}$, Dr. Gaurav Acharya ${ }^{2}$, Dr. Kishore Kumar Arora ${ }^{3}$
}

\begin{abstract}
Context: Better obstetric outcome is produced when ropivacaine is used for labour as compared to bupivacaine. Several studies insist on use of these drugs along with opioids. Aims: The following study compares bupivacaine and ropivacaine without opioids for labour epidural analgesia. Settings and Design: This prospective comparative study was conducted at a tertiary care hospital in central India. Methods and Material: A total of 60 parturient were randomly allocated into two groups to receive labour epidural analgesia with $10 \mathrm{ml}$ each of $0.125 \%$ bupivacaine or 0.2\%ropivacaine as main dose. A sensory level block of T10-L1 in the first stage of labour and a level of T10-S4 was achieved during 2nd stage of labour. A top up dose of $5 \mathrm{ml} 0.125 \%$ bupivacaine or $5 \mathrm{ml} 0.2 \%$ ropivacaine were given to the two groups respectively to patients complaining of pain. Labour was managed according to institutional standard labour protocols. Statistical analysis used: The data was collected using Microsoft Excel software and was analysed using SPSS software version17.0. Results: The onset was faster in bupivacaine group (mean $16.17 \pm 2.214$ min) as compared with ropivacaine group (mean $22.07 \pm 3.039 \mathrm{~min})$. The duration of analgesia was prolonged in ropivacaine group (mean $182.83 \pm 41.37$ min.) as compared to bupivacaine group (mean $161.33 \pm 3.25 \mathrm{~min}$ ), number of top ups given in bupivacaine group were higher. However there was no difference in any other obstetric or neonatal outcomes. Conclusions: $0.2 \%$ ropivacaine is better for labour analgesia suggested by superior quality and intensity of analgesia according to Visual Analog Scale; less requirement of top ups; better maternal satisfaction.
\end{abstract}

Keywords: bupivacaine, ropivacaine, labour analgesia, opioid

Key Messages: A comparison of bupivacaine and ropivacaine without opiods for labour epidural analgesia.

\section{Introduction}

Highly effective pain relief for labour and delivery can be achieved by epidural analgesia with the limitations of motor blockade and cardiovascular toxicity. Maternal mobility is affected by motor blockade and may prolong labour ${ }^{1}$. Unintentional intravenous bupivacaine injection results in maternal cardiac arrest and death ${ }^{2}$.

Still bupivacaine remains the most often used local anaesthetic for labour epidural analgesia. Ropivacaine was developed in an attempt to reduce bupivacaine-induced side effects and cardio toxicity. Ropivacaine is similar in structure and anaesthetic properties however it is less cardio toxic in animals. Ropivacaine producing less motor block as it is more selective for sensory fibres compared with other local anesthetics suggesting that ropivacaine could be superior to bupivacaine in labour epidural analgesia ${ }^{2}$. Studies where $0.5 \%$ ropivacaine was used for caesarean section showed no maternal or foetal side effects. Similarly, studies where $0.25 \%$ ropivacaine solutions was used for labour epidural analgesia showed no harmful maternal and neonatal effects and provided analgesia as effective as $0.25 \%$ bupivacaine ${ }^{3}$.

The objectives of the present study were to compare the effects of $0.2 \%$ ropivacaine with $0.125 \%$ bupivacaine on efficacy and motor block, need of top ups of drugs and to compare the effects of both drugs on neonatal outcome as determined by APGAR Score and maternal satisfaction.

\section{Subjects and Methods}

With approval from the Ethical Committee of our hospital and written informed consent from patients, 60 ASA physical status I and II women of the age group 18-35 years were taken for the study over a period of one year as per convenient sampling. Only booked primi/multigravida patients with full term singleton pregnancy (gestational age between 37-42 weeks) in active phase of $1^{\text {st }}$ stage of labour with good uterine contractions and cervical dilatation 3-5 cm were included. Patients not giving consent, allergic to local anaesthetics, patients with bleeding diathesis or on anticoagulant therapy or history of prolonged aspirin ingestion, patients with pre-existing neurological or spinal disease, cardiovascular or respiratory impairment, local or systemic infection, cephalopelvic disproportion, previous history of caesarean section or complicated labour or any complication of pregnancy like obstetric haemorrhage, eclampsia etc, or foetal distress i.e. non-reassuring foetal heart rate (FHR) prior to procedure were excluded. We explained and demonstrated the use of a $100-\mathrm{mm}$ visual analog scale ruler to these parturient for quantification of their pain at the peak of uterine contractions $(0 \mathrm{~mm}=$ no pain and $100 \mathrm{~mm}$ = worst pain). Parturient were randomly allocated to either the bupivacaine group $(n=30)$ or ropivacaine group $(n=30)$ based on a computer-generated random number list. Blinding was done by preparing the local anaesthetic solutions by an anaesthesiologist or one of the investigators who was not involved in subsequent patient assessment or management. After intravenous prehydration with $20 \mathrm{ml} / \mathrm{kg}$ or $1000 \mathrm{ml}$ of lactated Ringer's solution, an epidural catheter was inserted using aseptic precautions under local anaesthesia at the L2-3 or L3-4 intervertebral space using a loss-of-resistance technique. An epidural test dose of $3 \mathrm{ml}$ of lidocaine $2 \%$ with epinephrine 1:200,000 was given. All epidural injections were given slowly in incremental doses directly talking to and evaluating the patient. Patients were given $3+10 \mathrm{ml}=13 \mathrm{ml}$ of $0.125 \%$ bupivacaine and $3+10 \mathrm{ml}=13 \mathrm{ml}$ of $0.2 \%$ ropivacaine respectively. The table was tilted to achieve sensory level block of $\mathrm{T}_{10} \mathrm{~L}_{1}$ in $1^{\text {st }}$ stage of labour without paralysis of perineal muscles $\left(\mathrm{S}_{2}-\mathrm{S}_{4}\right)$. Continuous pulse, blood pressure monitoring was done at 2 min intervals for $1^{\text {st }} 30$ min after injection and then every 15 min. FHR was monitored every 


\section{International Journal of Science and Research (IJSR) \\ ISSN (Online): 2319-7064 \\ Index Copernicus Value (2013): 6.14 | Impact Factor (2014): 5.611}

15-20 min and continuous $\mathrm{SpO}_{2}$ monitoring done. In case any patient complained of discomfort or slight pain, top up dose of $5 \mathrm{ml} 0.125 \%$ bupivacaine and $5 \mathrm{ml} 0.2 \%$ ropivacaine were given to the two groups respectively. Progress of labour and cervical dilatation was assessed every 30-45 minute by the obstetrician. Upon entering $2^{\text {nd }}$ stage of labour, patient was placed in $30^{\circ}$ head up tilt or sitting position after top up dose to block the pain of perineal stretching, thus achieving sensory level of block of $\mathrm{T}_{10}-\mathrm{S}_{4}$. The onset of pain relief and the need for subsequent top ups were noted. Level of analgesia was checked. Sensory level checked by temperature, touch and pressure. Motor block assessed by modified bromage scale, Assessment of pain was done by 0-10 Visual analogue pain scale (VAS). All patients were observed for nausea, vomiting and pruritus. After the delivery of baby, neonatal APGAR scores were studied and mother was followed-up in puerperium for development of headache, hypotension, backache, fever etc. A patient satisfaction score for the labour epidural analgesia (average, excellent, good) was obtained. The data was collected using Microsoft Excel software and was analysed using SPSS software version 17.0.

\section{Results}

A total of 60 patients were assessed; 30 received $0.125 \%$ bupivacaine and 30 received $0.2 \%$ ropivacaine. The groups were well matched for age, height, weight, gravid and cervical dilatation.

The mean onset time for pain relief was $16.17+-2.214$ min in the bupivacaine group and 22.07+-3.039 $\mathrm{min}$ in the ropivacaine group $(P<0.0001)$. The median duration of pain relief was $161.33+-30.25 \mathrm{~min}$ in the bupivacaine group and $182.83+-41.37 \mathrm{~min}$ in the bupivacaine group.

Maternal systolic and diastolic arterial pressures, heart rate and foetal heart rate changed similarly in both groups. 25 patients of bupivacaine group and 23 patients of ropivacaine group were pain free at 30 minutes. 8 patients of bupivacaine group and 5 patients of ropivacaine ropivacaine had some pain during first stage of labour and 12 patients of bupivacaine group and 9 patients of ropivacaine group had pain during second stage of labour.

Maternal systolic and diastolic arterial pressures, heart rate and foetal heart rate changed similarly in both groups.

All patients received $10 \mathrm{ml}$ drug as main dose. 17 patients of bupivacaine group and 20 patients of ropivacaine group received $5 \mathrm{ml}$ of top up drug where as 9 patients received 10 $\mathrm{ml}$ of bupivacaine as top up and 2 patients required $10 \mathrm{ml}$ ropivacaine. No of top ups required in ropivacaine group were significantly less.

Motor blockade was $0^{\circ}$ in 22 patients and $1^{\circ}$ in 8 patients in bupivacaine group where as in ropivacaine group it was 24 patients and 6 patients respectively. T6 level was achieved in no patient in bupivacaine group and in 1 patient in ropivacaine group. T8 level was achieved in 20 and 17 patients in respective groups and T10 level in 10 and 12 patients respectively. T8 level was achieved in $61.7 \%$ patients.
In bupivacaine group, 10\% parturient had lower segment caesarean section and 90\% women delivered spontaneously. In group b $6.7 \%$ parturient were taken for LSCS while remaining 93.3\% parturient delivered spontaneously. Nausea and pruritis occurred in 3 and 1 patients respectively in bupivacaine group whereas no side effects were seen in ropivacaine group. An Apgar score of $>7$ at 1 minute was achieved in 14 patients and 19 patients respectively in bupivacaine and ropivacaine groups. Whereas a score of $>7$ was achieved in all the patients at 5 minutes. In bupivacaine group $56.7 \%$ women showed good satisfaction, $26.7 \%$ women were found to have average satisfaction and remaining $16.7 \%$ women experienced excellent satisfaction. Where as in ropivacaine group 50\% women showed good satisfaction, 33.3\% women were found to have average satisfaction and like bupivacaine group $16.7 \%$ women in this group showed excellent satisfaction.

\section{Discussion}

The ideal local anaesthetic agent for labour epidural analgesia should produce effective and controllable sensory block with rapid onset and prolong duration of action. It should produce minimal motor block. High therapeutic index and minimal placental transfer are other desired features. Bupivacaine fits with most of these properties but is known to produce clinically significant motor block with repeated dosage but is cardio toxic if injected intravenously ${ }^{4}$.

Ropivacaine which is single S-enantiomers found to be less cardio toxic than bupivacaine in human volunteers after IV administration. Scott and colleagues analyzed the electrocardiogram and came to the conclusion ${ }^{4}$. Reports suggest the use of low dose bupivacaine and ropivacaine along with fentanyl for labour epidural analgesia ${ }^{5-9}$ however use of low dose bupivacaine and ropivacaine alone without fentanyl have not been reported. Study results suggest that bupivacaine and ropivacaine alone provide equally effective analgesia with no associated maternal and foetal side effects. This is the first report of using low dose $0.125 \%$ bupivacaine and $0.2 \%$ ropivacaine alone without opioid for labour epidural analgesia.

In our study we found that both $0.125 \%$ bupivacaine and $0.2 \%$ ropivacaine $10 \mathrm{ml}$ followed by a top-ups of $5 \mathrm{ml}$ given in lumber epidural produced effective, tolerable labour analgesia. The time of onset of bupivacaine was significantly shorter than that of ropivacaine; there were no other significant differences in the quality of block. Similar observations have been reported in other studies where no difference was found in the onset or maximum height of block with $0.5 \%$ and $0.75 \%$ concentrations of each drug ${ }^{10}$, or with $0.75 \%$ concentrations of each drug with adrenaline ${ }^{11}$. We also found that duration of action was prolonged in ropivacaine group. However, another group comparing 0.5 $\%$ ropivacaine with $0.5 \%$ bupivacaine found that the sensory block of bupivacaine was slightly longer ${ }^{12}$.

It was an observation in our study that there was no difference in motor blockade in the two groups which is in conflict with the previous studies. Studies show that the ropivacaine produce less motor blockade with shorter duration of action as compared to bupivacaine at a higher 


\section{International Journal of Science and Research (IJSR) \\ ISSN (Online): 2319-7064 \\ Index Copernicus Value (2013): 6.14 | Impact Factor (2014): 5.611}

concentration ${ }^{10,13}$. In a study comparing $0.5 \%$ bupivacaine and $0.75 \%$ ropivacaine showed no significant difference in motor block ${ }^{14}$. Duration of motor blockade was found to be prolonged in some studies with no difference in onset or degree of block ${ }^{12}$.

Since the Bromage scale is a qualitative assessment of motor blockade it might not have been expected to provide quantitative assessment. Axelsson's method to assess motor blockade quantitatively can provide a more precise values of degree and duration of motor block ${ }^{15}$. In this method mean values of isometric contractions as a percentage of baseline value of muscle power are calculated. In a study where both Bromage and Alexsson's method were compared to measure the motor blockade after epidural ropivacaine, a difference of $1.5-2.5 \mathrm{~h}$ in full recovery of muscle power after the block was found ${ }^{15}$.

Thus in our study we conclude that the onset of analgesia was faster in bupivacaine group, quality and intensity of analgesia as assessed by VAS score better in ropivacaine group and required top ups were also less, there was no difference in sensory and motor blockade in either group, the progress of labour was good and mode of delivery was not significantly different in both the groups. $0.2 \%$ Ropivacaine without opioids was found to be better for the purpose of labour analgesia since it provides superior quality of analgesia according to VAS, less requirement of top ups, better maternal satisfaction, no complications like nausea, vomiting, pruritis were reported in both the groups, and the neonatal outcome was good in both groups.

\section{References}

[1] Lacassie HJ, Habib AS, Lacassie HP, Columb MO. Motor blocking minimum local anesthetic concentrations of bupivacaine, levobupivacaine, and ropivacaine in labor. Reg Anesth Pain Med.2007;32:323-9.

[2] Neal JM, Bernards CM, Butterworth JF, Di GG, Drasner K, Hejtmanek MR, et al. ASRA Practice Advisory on Local Anesthetic Systemic Toxicity. Regional Anesthesia \& Pain Medicine. 2010;35:152-61.

[3] Nogueira CS, Lima LC, Paris VC, Neiva PM, Otani ET, Couceiro RO, et al. Estudo comparativo entre bupivacaína (S75-R25) e ropivacaína em bloqueio peridural para analgesia de parto. Rev. Bras. Anestesiol. 2010; 60( 5 ): 484-94.

[4] Beilin Y, Halpern S. Ropivacaine Versus Bupivacaine for Epidural Labor Analgesia. Anesthesia \& Analgesia. 2010; 111(2):482-7.

[5] Bajwa SJS, Bajwa SK, Kaur J. Comparison of epidural ropivacaine and ropivacaine clonidine combination for elective cesarean sections. Saudi Journal of Anaesthesia. 2010;4(2):47-54. doi:10.4103/1658354X.65119.

[6] Pandya ST. Labour analgesia: Recent advances. Indian Journal of Anaesthesia. 2010;54(5):400-8.

[7] Chhetty YK, Naithani U, Gupta S, Bedi V, Agrawal I, Swain L. Epidural labor analgesia: A comparison of ropivacaine $0.125 \%$ versus $0.2 \%$ with fentanyl. J Obstet Anaesth Crit Care 2013;3:16-22
[8] Li Y, Hu C, Fan Y, Wang H, Xu H. Epidural Analgesia with Amide Local Anesthetics, Bupivacaine, and Ropivacaine in Combination with Fentanyl for Labor Pain Relief: A Meta-Analysis. Medical Science Monitor: International Medical Journal of Experimental and Clinical Research. 2015;21:921-8.

[9] Dresner M, Freeman J, Calow C, Quinn A, Bamber J. Ropivacaine $0.2 \%$ versus bupivacaine $0.1 \%$ with fentanyl: a double blind comparison for analgesia during labour. Br. J. Anaesth. 2000; 85 (6): 826-9.

[10] Chandran S, Hemalatha S, Viswanathan $\mathrm{P} \quad \mathrm{N}$. Comparison of $0.75 \%$ ropivacaine and $0.5 \%$ bupivacaine for epidural anaesthesia in lower extremity orthopaedic surgeries. Indian J Anaesth 2014;58:336-8

[11] Lyons G, Columb M, Hawthorne L, Dresner M. Extradural pain relief in labour: bupivacaine sparing by extradural fentanyl is dose dependent. $\mathrm{Br} \mathrm{J}$ Anaesth 1997;78:493-7.

[12] Griffin RP, Reynolds F. Extradural anaesthesia for Caesarean section: a double-blind comparison of $0.5 \%$ ropivacaine with $0.5 \%$ bupivacaine. Br. J. Anaesth.1995; 74 (5): 512-516

[13] Kuthiala G, Chaudhary G. Ropivacaine: A review of its pharmacology and clinical use. Indian Journal of Anaesthesia. 2011;55(2):104-110.

[14] Chandran S, Hemalatha S, Viswanathan P. Comparison of $0.75 \%$ ropivacaine and $0.5 \%$ bupivacaine for epidural anaesthesia in lower extremity orthopaedic surgeries. Indian Journal of Anaesthesia. 2014;58(3):336-338.

[15] Axelsson K, Hallgren S, Widman B, Olstrin PO. A new method for measuring motor block in the lower extremities. Acta Anaestheiiohgica Scandanavica 1985; 29: $72-78$.

Table 1: Comparison onset and duration of analgesia (min) between the two groups

\begin{tabular}{|c|c|c|c|}
\hline Group & $\begin{array}{c}\text { onset of } \\
\text { analgesia }(\mathrm{min}) \\
\text { Mean } \pm S D\end{array}$ & $\begin{array}{c}\text { duration of } \\
\text { analgesia } \\
\pm S D\end{array}$ & $\begin{array}{c}\text { No. of } \\
\text { patients }\end{array}$ \\
\hline A & $16.17 \pm 2.214$ & $161.33 \pm 30.25$ & 30 \\
\hline B & $22.07 \pm 3.039$ & $182.83 \pm 41.37$ & 30 \\
\hline Total & $\mathbf{1 9 . 1 2} \pm 3.975$ & $\mathbf{1 7 2 . 0 8} \pm 37.53$ & $\mathbf{6 0}$ \\
\hline
\end{tabular}

$\mathrm{P}<0.0001$

Table 2: Quality of analgesia during labour in the both

\begin{tabular}{|l|c|c|c|}
\hline \multicolumn{1}{|c|}{ groups } \\
\begin{tabular}{|l|c|}
\hline \\
$(\mathrm{n}=30)$
\end{tabular} & $\begin{array}{c}\text { Group-B } \\
(\mathrm{n}=30)\end{array}$ & $\begin{array}{c}\mathrm{P} \\
\text { value }\end{array}$ \\
\hline Pain free at 30 min & 25 & 23 & 0.51 \\
\hline Analgesia during $1^{\text {st }}$ stage of labour \\
\hline VAS=0cm & 9 & 17 & 0.037 \\
\hline VAS $<1 \mathrm{~cm}$ & 15 & 18 & 0.43 \\
\hline VAS $<3 \mathrm{~cm}$ & 22 & 25 & 0.34 \\
\hline Analgesia during 2 ${ }^{\text {nd }}$ stage of labour \\
\hline VAS $=0 \mathrm{~cm}$ & 9 & 13 & 0.28 \\
\hline VAS $<1 \mathrm{~cm}$ & 12 & 14 & 0.60 \\
\hline VAS $<3 \mathrm{~cm}$ & 18 & 21 & 0.41 \\
\hline
\end{tabular}

$\mathrm{P}<0.05$ 
Table 3: Comparison of number of Top Ups

\begin{tabular}{|c|c|c|c|}
\hline No. of Top Ups & $A$ & $B$ & Total \\
\hline 0 & 4 & 8 & 12 \\
& $13.3 \%$ & $26.7 \%$ & $20.0 \%$ \\
\hline 1 & 17 & 20 & 37 \\
& $56.7 \%$ & $66.7 \%$ & $61.7 \%$ \\
\hline 2 & 9 & 2 & 11 \\
& $30.0 \%$ & $6.7 \%$ & $18.3 \%$ \\
\hline Total & $\mathbf{3 0}$ & $\mathbf{3 0}$ & $\mathbf{6 0}$ \\
\hline Mean \pm SD & $\mathbf{1 . 1 6} \pm \mathbf{0 . 6 7}$ & $\mathbf{0 . 8 0} \pm \mathbf{0 . 5 5}$ & \\
\hline
\end{tabular}

$t=2.27 ; P<0.05$

Table 4: Comparison of motor blockade

\begin{tabular}{|c|c|c|c|}
\hline Motor Blockade & $\mathrm{A}$ & $\mathrm{B}$ & Total \\
\hline $0^{0}$ & 22 & 24 & 46 \\
& $73.3 \%$ & $80.0 \%$ & $76.7 \%$ \\
\hline $\mathrm{I}^{0}$ & 8 & 6 & 14 \\
& $26.7 \%$ & $20.0 \%$ & $23.3 \%$ \\
\hline Total & $\mathbf{3 0}$ & $\mathbf{3 0}$ & $\mathbf{6 0}$ \\
\hline
\end{tabular}

$\chi^{2}=0.37 ; \mathbf{p}>0.05$

Table 5: Comparison of sensory blockade

\begin{tabular}{|c|c|c|c|}
\hline Level of sensory blockade & $\mathrm{A}$ & $\mathrm{B}$ & Total \\
\hline \multirow{2}{*}{6} & 0 & 1 & 1 \\
& $0.0 \%$ & $3.3 \%$ & $1.7 \%$ \\
\hline \multirow{2}{*}{8} & 20 & 17 & 37 \\
& $66.7 \%$ & $56.7 \%$ & $61.7 \%$ \\
\hline \multirow{2}{*}{10} & 10 & 12 & 22 \\
& $33.3 \%$ & $40.0 \%$ & $36.7 \%$ \\
\hline Total & $\mathbf{3 0}$ & $\mathbf{3 0}$ & $\mathbf{6 0}$ \\
\hline
\end{tabular}

$$
\chi^{2}=1.43 ; p>0.05
$$

Table 6: Comparison APGAR Score

\begin{tabular}{|c|c|c|c|c|c|c|c|}
\hline \multicolumn{4}{|c|}{ At 1minute } & \multicolumn{4}{|c|}{ At 5minute } \\
\hline \multirow{2}{*}{$\begin{array}{l}\text { APGAR } \\
\text { Score }\end{array}$} & \multicolumn{2}{|c|}{ Group } & \multirow{2}{*}{ Total } & \multirow{2}{*}{$\begin{array}{c}\text { APGAR } \\
\text { Score }\end{array}$} & \multicolumn{2}{|c|}{ Group } & \multirow[t]{2}{*}{ Total } \\
\hline & A & B & & & $\mathrm{A}$ & B & \\
\hline $5-7$ & $\begin{array}{c}16 \\
53.3 \%\end{array}$ & $\begin{array}{c}11 \\
36.7 \%\end{array}$ & $\begin{array}{c}27 \\
45.0 \%\end{array}$ & $5-7$ & 0 & 0 & 0 \\
\hline$\geq 7$ & \begin{tabular}{|c|}
14 \\
$46.7 \%$ \\
\end{tabular} & $\begin{array}{c}19 \\
63.3 \% \\
\end{array}$ & \begin{tabular}{|c|}
33 \\
$55.0 \%$ \\
\end{tabular} & $\geq 7$ & $\begin{array}{c}30 \\
100 \% \\
\end{array}$ & $\begin{array}{c}30 \\
100 \% \\
\end{array}$ & $\begin{array}{c}30 \\
100 \% \\
\end{array}$ \\
\hline Total & 30 & 30 & 60 & & 30 & 30 & 60 \\
\hline
\end{tabular}

$P>0.05$ 